\title{
Working Memory abilities, attachment relationships and learning process in children of primary school age: an empirical research
}

\author{
Nadia Del Villano $^{1^{*}}$, Claudia Cecere ${ }^{2}$, Walter Sapuppo ${ }^{1}$, Alessia Sannino ${ }^{2}$, \\ Raffaella Perrella ${ }^{2}$, Sara Bisogno ${ }^{2}$, \& Giorgio Caviglia ${ }^{2}$
}

\begin{abstract}
Several studies underline a definite link between working memory (WM) and the learning process (deficit and learning disorder in children). WM abi-lities mainly affect written language learning and arithmetic learning. According to studies related to the Attachment Theory, it is possible to rationalize that child with a secure attachment to the caregiver and/or to the teacher have higher skills in school adaptability. In this study-based on previous pilot study (Del Villano, Cecere, Sapuppo, \& Caviglia., 2011) - the relationship between: cognitive test (WM measurement test), learning test and the student's attachment style (both with his caregivers and his teacher) have been empirically evaluated. This pilot study was performed in several of the primary schools in Campania Italy between 2009 and 2011. The selected sample was composed of 80 children 6-7 years old ( 38 Female and 42 Male) who, after parental and school consent, were tested by the tools described in the main body of this research paper. The pilot study shows an absence of linguistic deficit, and a relationship between cognitive abilities and the learning le-vel achieved in reading and mathematical calculation, furthermore it has shown a modulation effect of the attachment on the relationship between the WM ability and MT calculation and reading tests. This modulation effect is more evident if we consider the unsecure or disorganized attachment, especially if we consider the data accumulated with reference to the attachment to the teacher. Our research was conducted with the sole intention to widen the sample and make the outcomes more valid and reliable. The recruited sample was composed of 130 children age 6-7 who, after parenentalt and school consent, were tested with the TVL -Linguistic Assessment Test, the short version of AWMA (Automated Working Memory Assessment), the SAT-Separation Anxiety Test, both family and school versions, and the Reading Trials MT -AC-MT 6-11- Calculation Ability Assessment Test. The results underline the absence of deficit or malfunctions in the subjects' linguistic development, a significant connection between the learning performances and the verbal and visual-spatial trials assessed with the AWMA, and a moderating effect of the attachment style upon the connection itself.
\end{abstract}

Keywords: working memory, learning, attachment

\footnotetext{
${ }^{1}$ Dipartimento di Psicologia, Seconda Università degli Studi Napoli; Scuola di Specializzazione in Psicologia Clinica, Facoltà di Medicina e Psicologia, Sapienza di Roma. E-mail: delvillano.1237007@studenti.uniroma1.it.

${ }^{2}$ Dipartimento di Psicologia, Seconda Università degli
}

Studi di Napoli.

*Correspondence concerning this article should be addressed to Nadia Del Villano, Dipartimento di Psicologia, Seconda Università degli Studi di Napoli.

E-mail: delvillano.1237007@studenti.uniroma1.it 
In 1968, Atkinson and Shiffrin suggested a Multi Store Memory Model, consisting of three different stores, through which it is possible to consider the information: the Sensory Memory (SM), the Short-Term Memory (SMT) and the Long-Term Memory (LTM) (Atkinson \& Shiffrin, 1971). In 1974 Baddeley and Hitch proposed a new model of Working Memory (WM), in order to accurately define the dynamics of the STM. The results of their study questioned the vision of a homogeneous system of STM; this led to the formulation of the WM model as an alternative to the traditional double storage models. The WM concept refers to a hierarchical system which maintains and temporary processes the information, during the execution of different cognitive tasks (Baddeley \& Hitch, 1974). The authors first proposed a model made up of three main components: the Central Executive System (CES), the articulatory loop (or ring), and the visual-spatial sketchpad. In 2000 Baddeley modified this model with the Working Memory model shown in the figure 1 below.

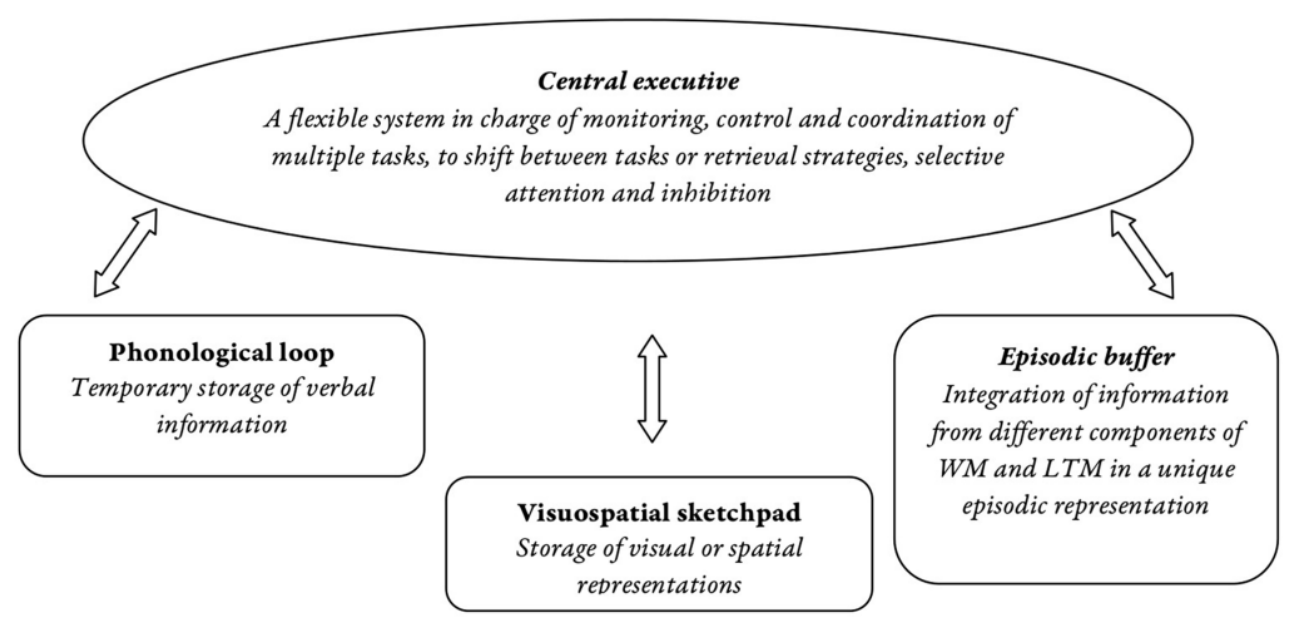

Figure 1. Working memory (Baddeley, 2000)
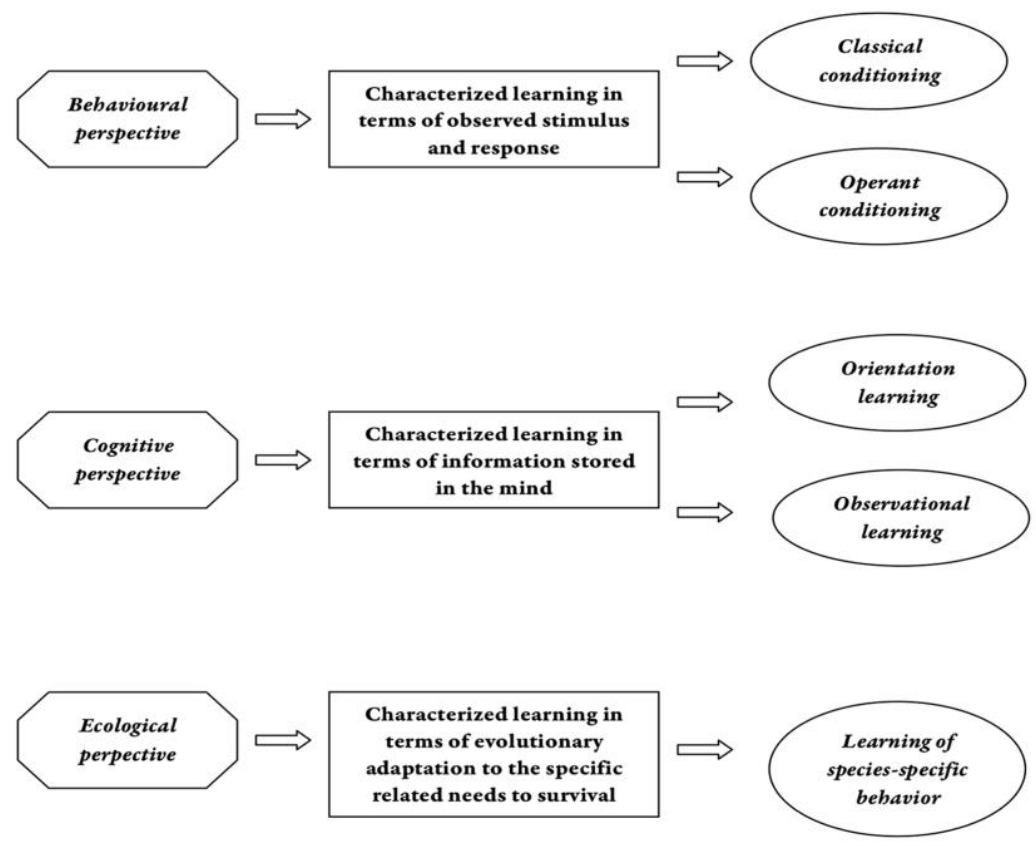

Figure 2. Different models of learning processes 
Learning process can be seen as the process with which an actual lived experience at a given time is able later to influence and/or change the individual behavior (Gray, 2004). In learning process studies, it is possible to identify different theoretical profiles as shown in the Figure 2 (the previous chart has been drawn by the authors of this pilot study).

According to the Bowlby attachment theory (1972, 1975, 1983), the attachment bond is an exclusive and durable relationship that the individual establishes with his/her caregiver and takes place since the beginning within a dyadic relationship matrix with its internal mechanisms and relationship with the external environment (Caviglia, 2003). According to Bowlby, the infant has an innate and biological predisposition to develop an attachment bond towards those who take care of his/her (caregivers), this bond has the biological function of ensuring protection for the child and to provide psychological security. As noticed by Ainsworth (Ainsworth \& Witting, 1969), and later by Main and Solomon (1990), it is possible to identify four caregiver?child attachment patterns: Secure "B" type, Insecure-avoidant "A" type, Insecure-resistant/ambivalent "C" type, and Disorganized "D" type.

In the modern society we can say that the monotropy concept (turn in one direction), developed by J. Bowlby in his attachment theory, seems not to have perfect applicability because since at early age, children establish attachment bonds with other adults, grandparents, uncles, and teachers. Beyond the childcaregiver attachment, it is possible to identify other attachment relationships with other caregivers (Liverta Sempio, Marchetti, \& Lecciso, 2001). As noted the other attachment styles-established with others than the key people-can influence the emotional and cognitive functions of expression and the learning "level" achieved by each child.

\section{Working Memory, Learning and Attachment: what Connections?}

When we administered the tests to the chosen sample, we didn't know in advance if the chosen people were pathological or not. Since we wanted to avoid focusing only on the dysfunctional dimension, we didn't recruit children with deficits just to note the differences between normal and pathological children. Many studies show a strong link between Working Memory (WM) deficits and the learning disorders in children. WM abilities specifically affect written and arithmetic language (Alloway, 2012; Alloway \& Passolunghi, 2011; Alloway \& Temple, 2007; Caviglia, La Marra, Sapuppo, \& Perrella, 2010). It seems that also relationships with adults and peers have a considerable influence on good psychophysical child development, on the cognitive and/or affective-relational expressions and the proper Self perception. Based on the studies carried out in the attachment theory context (Caviglia, \& De Coro, 2002; Caviglia, Fiocco, \& Dazzi, 2004; Caviglia,
Iuliano, \& Perrella, 2005; Caviglia, Perrella, Sapuppo, \& Del Villano, 2010; Perrella, Semerari, \& Caviglia, 2013 ) it is possible to emphasize that children with a secure attachment with their caregivers and/or with their teachers, show better skills in the recognition and emotional expression, in prosocial behavior, in recreational-cognitive acquisition of basic concepts, in educational adaptation and in linguistic-expressive development (Cassibba, \& Caviglia, 2001; Caviglia, 2003; Caviglia, 2005; Meins, 1999; Pianta, 1999; Pianta, Nimez, \& Bennett, 1997). Every child from birth is inserted in a relational/social network that involves a lot of people that can influence-in a different ways -his psychophysical and emotional-relational development. After the early age, also other relational contexts-other than family - may have more or less direct impact on the overall child psychophysical and relational development (Cassibba, 2005; Liverta Sempio et al., 2001). A growing number of studies highlight the importance of the teacher as an attachment individual, able to provide a growing and development context, considering that children since first entering the school, spend their time principally with two adults figures: parents and teachers (Bergin \& Bergin, 2009; Curby, Rimm-Kaufman, \& Ponitz, 2009; Howes, Galinsky, \& Kontos, 1998; Howes, 1999; Pianta, Belsky, Vandergrift, Houts, \& Morrison, 2008; Sagi, van Ijzendoorn, Aviezer, Donnell, KorenKarie, Joels, \& Harel, 1995), furthermore, secure children appeared to be more competent in the language domain than insecure children. Language development appears to be more stimulated in the context of a secure attachment relationship (van Ijzendoorn, Dijkstra, \& Bus, 1995).

Based on our previous pilot study carried out in 2010, we have introduced in this research new assessment tools, we have expanded the sample and reduced the age range of the children attending primary school, in order to make results and conclusions more reliable. This empirical research aims to a twofold objective: to verify the link between the WM abilities and the learning level achieved by the children, and to verify if the relationship is affected or moderated by the attachment style that the child develops with parents and teacher figures. Different tools have been used for the assessment: the short version of the Automated Working Memory Assessment (AWMA) that assesses the efficiency of the various working memory subsystems, the MT reading test and the AC-MT 6-11 -Calculation ability assessment Test, both for linguistic and numerical learning tests assessment, and a semi-projective test (Separation Anxiety Test; SAT) to assess the attachment style that the child establishes both with their parents and the teacher. We expect that a greater WM ability is linked with an increased learning ability in both considered domains. Moreover, given the importance of the attachment relationship, we expect that attachment style, towards their parents and towards the teacher 
will moderate the connection.

This study arises from the evolutionary psychology that helps to use the knowledge derived from the normal and pathological child development and its correlation to the clinical manifestation in adulthood.

\section{Method}

\section{Sample}

$N=130$ children were randomly selected ( 61 females and 69 males), from different schools in Campania, Italy. Their ages ranged from 6 to 7 years $(M=6.4 ; S D$ $=0.5$ ), and each participant had been given parental and school authorization to participate in the project.

This project was proposed to the management of several schools as $\mathrm{PhD}$ final dissertation, as an university dissertation and Prin. The school management authorized the research and cooperated with us. Then the research was presented to the teachers, then to the parents with a formal letter from the schools. For each child, both parents signed the consent to allow their child to participating in the research project, and according to the information provided by the teachers, no significant social-economic differences were noted among the recruited children.

The tests administered to all participants were; $\mathrm{Lin}$ guistic Assessment Test (TVL; Cianchetti \& Sannio Fancello, 2007), the short version of the Automated Working Memory Assessment (AWMA; Alloway, Gathercole, Willis, \& Adams 2004), the Separation Anxiety Test (SAT), both in family version (Attili, 2001) and school version (Liverta Sempio et al., 2001), and two different achievement tests for the learning level: Reading Tests $M T$ and AC-MT 6-11 - Skill Calculation Assessment Test (Cornoldi \& Colpo, 1998; Cornoldi, Lucangeli, \& Bellina, 2002).

We decided to recruit 6-7 year old children for the following reason: at this age it is possible to assess the learning abilities (before this age children are not able to read, etc.), but it is not possible to diagnose learning disorders (generally diagnosed after 8 years), therefore, we can only highlight some specific difficulties (reading, writing, mathematics calculation). The early identification of specific difficulties may encourage immediate action to prevent the disorder from developing fully. It is not completely correct to talk about prevention at the age of 6-7 years (the diagnosis should be made between 4-5) but definitely we can talk about a strengthening of skills and cognitive functions related to the learning, and this might be useful to compensate for and / or improve the learning level of specific skills (Cornoldi, 2007). Furthermore, the purpose of this work was to detect, if it exists, the correlation between WM, learning and attachment, not to assess any learning disorder. Any intervention for any learning disorder would be the domain of the parents and teachers.

- Each administration of the assessment tool took place in specific classrooms provided by the respective departments. The duration of the assessment and the method of administration (individual and group) were carried out taking into account the standardization input of each tool. Linguistic Assessment Test (TVL). The TVL is a tool that allows one to assess and quantify the overall child level development and to highlight any differences and/or abnormalities in the evolution of the various components and linguistic expressions. The TVL was administered in order to determine whether any participant already exhibited a lack of language development. The test was validated with a sample of 446 children ( 240 males and 206 females) aged between 2 years and 6 months to 5 years and 11 months. In addition, 41 children (27 males and 14 females) were re-tested within 15 days after the first administration (Cianchetti \& Sannio Fancello, 2007, pp. 111?113). The test-retest correlation gave the following Pearson scores: understanding words r .91, understanding phrases .90 , total comprehension .93 , repetition .87 , denomination .96 , correct phonological .59, morpho-syntactic correctness .46, construction .53 , sentence construction period $\mathrm{a} / \mathrm{i}$ .65 , construction period $\mathrm{s} / \mathrm{p} .69$, average utterance length .31, style .74. The multiple linear regression analysis on the raw scores performed on the scales with reference to the age, gave the following R2 (coefficient of fit of the linear regression model) values: comprehension .55 , repetition .43 , denomination .49, spontaneous production .29. Considering all other parameters, the relationship with the age variable is highly significant with $\mathrm{p}<.001$ ( $\mathrm{T}$ Student test).

- Automated Working Memory Assessment (AWMA). To assess the different working memory components (WM) - as described in the theoretical model developed by Baddeley and Hitch (1974) - the short version of the AWMA has been used. The tool consists of the following four main subtests:

(1) Digit recall: the subject is asked to listen to a numerical sequence and repeat it with the same presentation order (verbal test);

(2) Dot matrix: the subject is asked to see a signal stimulus within a matrix and then to remember the exact location (visual-spatial test);

(3) Spatial recall: the subject is asked to identify the correct spatial location of a rotated figure and a coloured signal stimulus position (visual-spatial test);

(4) Listening recall: the subject is asked to judge a statement as true or false and remember the last word of the same statement (verbal test).

Two additional subtests have been added to the above four subtests, these subtests assess the processing level adopted by the subject to analyze the necessary information to provide the answer to the 
given task. These subtests are: Processing spatial recall and Processing listening recall. For each subtest, the software administers a number of increasing complex trials. At the end of the test, the computer automatically assigns a score that quantifies the ability of the subject in the specific working memory component assessed, both verbal and visual-spatial. Test reliability of the AWMA was measured on 128 individuals randomly selected across schools and universities aged between 4.10 years to 22.5 years (Alloway, 2007, p. 56).

Scores obtained by testing referred to the Pearson correlation are: digit recall .89 , dot matrix .85 , listening recall .88 , listening recall processing .84 , spatial recall .79, and spatial recall processing .76. Authors evaluated the efficacy of using the AWMA to reliably screen individuals with working memory problems. In total $75 \%$ of children with poor working memory on the basis of identification by the AWMA also obtained standard scores of 85 or less on the WISC-IV Memory Index (Alloway, 2007, p. 60).

- Separation Anxiety Test (SAT). To obtain the Internal Working Models (IWM), Separation Anxiety Test (SAT) family version (Attili, 2001) and school version (Liverta Sempio et al., 2001) was used. The SAT is a semi-projective test based on a series of illustrations depicting separation scenes between a child and his/her parents in the family version, and between a child and his/her teacher in the school version. The different scenes activate the representations that the child has of the attachment relationship; it allows classifying the representations into three categories (Secure; Insecure and Disorganized). The SAT was oriented so that the characters depicted in the stories had the names and/or the ages as the child being tested. SAT family directions are the follows: "I would like you to help me to understand what children feel when their parents sometimes, have to go way and have to leave them alone for a while. Generally speaking, some children feel lonely, others remain happy, others get angry, and some are afraid. I have some drawings in which there is a child the same age as you; now I will ask you some questions (Attili , 2001). SAT School directions are as the follows: "I have some pictures of a child who has your same name and I would like you to help me to tell some stories about him/her. Do you agree?" (Liverta Sempio et al., 2001).

Each child was provided with hints, the hints should stimulate the child to answer but never suggest it nor condition it. SAT school version does not differentiate between insecure ambivalent and insecure avoidant, for this reason we chose to not insert it in the SAT for family as well, in this way the measures and categories taken in account were kept consistent.

As one of the SAT reliability measures, the interjudges agreement was evaluated. The agreement de- gree among the judges was high, in fact, the Pearson's $r$ is 0.95 (Liverta Sempio et al., 200, pp. 90-91). For the SAT family, the test-retest and inter-judges reliability were verified (Attili, 2001, pp. 88-92). The correlations, calculated with the two-tailed Spearman test between the final scores of the first and second administration, were positive. With regard to the reliability between the judges, the percentage of agreement on the total scores was $80 \%$ (Cohen's kappa $=.75, p<$ $.001)$. The SAT concurrent validity was verified by checking that the secure attachment relationship was linked with other constructs, in the expected direction of the attachment. The results showed a positive link between attachment and the understanding of the mind.

The tools administration sequence was: TVL; AWMA; MT trials, SAT. Only for some math and reading trials, the group administration was chosen, in line with the foreseen possibility of the tools. Children received only the appropriate hints.

MT trials were used because they inform us if the learning level achieved (in each subject by the child), is within the average or requires an intervention (because there is a deficit).

Reading Tests MT and AC-MT 6-11 - Skill Calculation Assessment Test. These tests allow one to assess the reading tasks level reached by each student (text comprehension, accuracy/number of errors and time spent in reading a text sample) and to calculate task levels reached by each student (written calculation, numerical knowledge, accuracy and speed of calculations perform). For each test according to the literature, raw scores with reference to the age, were converted into $\mathrm{z}$ points and/or percentile, and a standardized score was assigned, which allows one to assess the subject's performance, and also illustrate it graphically (good, fair, attention request, request for immediate intervention).

The test-retest reliability of the AC-MT 6-11, has been checked on a group of 261 individuals who were re-examined with the tests after one month. The Pearson coefficient was calculated to evaluate the different correlations between the test's trials for all participants of the selected classes in the primary school. The average correlation of all classes and all tests was .65 (Cornoldi et al., 2002, pp. 39?40). In order to evaluate the concurrent test validity, the authors have correlated the test scores with the opinion expressed by teachers. The correlations outcomes are significant at .01 level and the correlation average is .51 (Cornoldi et al., 2002, p. 41-42). The correlations between the reading tests give high values for accuracy and speed (Pearson's r .90).

\section{Data Analysis}

In order to carry out a data descriptive analysis and to compare the different attachment styles among them assessed with SAT (school and family), the data were 
inserted into a contingency table, and then a chi2 and a residue standards analysis were performed.

In order to compare the participants' performances on the WM functioning and on the learning level, the data were analyzed using four multivariate analysis of variance (MANOVA) with a single factor, the attachment styles (both toward the parents and the teacher) as the independent variables with three levels and the AWMA subtests or learning trials as the dependent variables were selected.

In order to assess the degree of association between the WM ability and the learning level achieved by children, the Pearson coefficients correlation were calculated between AWMA subtests and learning trials. All coefficients were interpreted according to the Cohen's effect size (Cohen, 1988). In order to assess whether the kind of attachment moderates the relationship between the WM ability and the learning level, moderation analysis as suggested by Baron and Kenny (Baron \& Kenny, 1986) were performed. Moreover, to interpret the moderation effects, the Pearson correlation coefficients were calculated between the AWMA subscales and the learning tests subscales, depending on the type of task and kind of attachment. For all the analysis the $\alpha .05$ value was set.

To control the increasing of type I error, we applied Hommel's correction to the p-values of the correlation coefficients (Hommel, 1988).

\section{Results}

\section{Relationship between attachment measures.}

The Chi Square analysis (Table 1) conducted to compare the different attachment styles showed a significant association between the two classification scales, Chi Square $(4, N=130)=20.69, p<.001$.

The standard residuals analysis, showed that children with secure attachment with their caregivers, establish, with a greater probability, a secure attachment with their teacher $(R=2.3)$ rather than the children who have an insecure or disorganized attachment $(R$ $=-1.2$ or $R=-1.5$, respectively). Children who have a disorganized attachment with their caregiver, showed, with greater probability, a disorganized attachment relationship with their teacher $(R=1.9)$ rather than a secure attachment $(R=-2.5)$. In children with an insecure attachment with their caregiver, we didn't observe any relationship with reference to the attachment style established with their teacher.

\section{Attachment style effect of the selected variables}

The MANOVA analysis performed on the AWMA subtest showed no significant effects of attachment style both towards parent Wilks lambda $=.847$, $\mathrm{F}(12,244)=1.76, \mathrm{p}=.055$, and to the teacher, Wilks lambda $=.861, \mathrm{~F}(12,244)=1.58, \mathrm{p}=.099$.

The MANOVA analysis conducted on the learning
Table 1. Contingency table of comparison between the different attachment styles established that emerged from the two different SAT (family and school)

SCL-90-R

\begin{tabular}{|c|c|c|c|c|}
\hline SAT Family & 苞 & 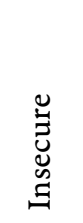 & 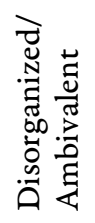 & ت્ّ \\
\hline Secure & 27 & 9 & 6 & 42 \\
\hline \% Row & 64.3 & 21.4 & 14.3 & 100 \\
\hline $\begin{array}{l}\text { Standardized } \\
\text { Residuals }\end{array}$ & $2.3^{*}$ & -1.2 & -1.5 & 77 \\
\hline $\begin{array}{l}\text { Corrected } \\
\text { Residuals }\end{array}$ & $3.6^{*}$ & -1.8 & $-2.1^{*}$ & 94 \\
\hline Insecure & 23 & 19 & 14 & 56 \\
\hline \% Row & 41.1 & 33.9 & 25 & 100 \\
\hline $\begin{array}{l}\text { Standardized } \\
\text { Residuals }\end{array}$ & -0.1 & 0.2 & -0.2 & \\
\hline $\begin{array}{l}\text { Corrected } \\
\text { Residuals }\end{array}$ & -0.1 & 0.3 & -0.3 & \\
\hline $\begin{array}{l}\text { Disorganized } \\
\text { /Ambivalnt }\end{array}$ & 4 & 14 & 14 & 32 \\
\hline \% Row & 12.4 & 43.8 & 43.8 & 100 \\
\hline $\begin{array}{l}\text { Standardized } \\
\text { Residuals }\end{array}$ & $-2.5^{*}$ & 1.1 & 1.9 & \\
\hline $\begin{array}{l}\text { Corrected } \\
\text { Residuals }\end{array}$ & $-3.8^{*}$ & 1.6 & $2.6^{*}$ & \\
\hline Total & 54 & 42 & 34 & 130 \\
\hline \% Row & 41.5 & 32.3 & 26.2 & 100 \\
\hline
\end{tabular}

tests showed significant effects of attachment style towards both parents, Wilks lambda $=.729, F(14$, $242)=2.96, p<.001$, Chi Square $p=.146$, and to the teacher, Wilks lambda $=.757, F(14,242)=2.59, p=$ .002 , Chi Square $p=.130$. Subsequent univariate analysis of va-riance (ANOVA) confirmed that the attachment style effect towards a child's parents can be noticed in all considered measures, while the attachment style towards the teacher affects only some of the measures (see Table 1). Post hoc conducted with Scheffè correction (Tabachnick \& Fidell, 1983), 
showed that regardless of the measures, children classified as "Secure" show better performance than those classified as "Ambiguous/Disorganized." An intermediate position is assigned to the "Insecure".

\section{Relationship between WM and learning}

Correlation analysis showed a significant association between WM ability and the learning performances achieved on both the reading and calculation tests.

The data relating to the reading test showed that the WM ability is mainly associated to the Understanding test performance, although all coefficients indicated a small association, but it seems they didn't have any association with the number of errors and the time needed to perform the test. In particular, both Dot matrix subtests, Listening recall and Spatial recall, and processing level subtests, Listening recall processing and Spatial recall processing, show a positive correlation with the text comprehension test (see Table 2). In all cases, greater skill is associated with a greater text understanding. Relationship between the Digit recall subtest and reading skills is not significant.

Table 2. Correlation matrix between AWMA scores on the subscales and Reading Test MT $(\mathrm{N}=130)$

\begin{tabular}{|c|c|c|c|}
\hline \multirow[b]{2}{*}{ AWMA subtests } & \multicolumn{3}{|c|}{ Reading Test MT } \\
\hline & 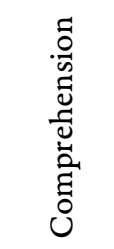 & 苞 & $\underset{:}{\stackrel{\Xi}{\mid}}$ \\
\hline Digit recall & .106 & .054 & .032 \\
\hline Dot matrix & $.164^{*}$ & -.077 & -.047 \\
\hline Listening recall & $.198^{*}$ & -.018 & .081 \\
\hline Spatial recall & $.164^{*}$ & -.104 & .057 \\
\hline Processing Listening recall & $.221^{* *}$ & -.035 & .073 \\
\hline Processing Spatial recall & $.157^{*}$ & -.026 & .116 \\
\hline
\end{tabular}

As illustrated in Table 3, data show that the WM abilities are mainly associated to the performance in the numerical knowledge test, while they seem to have no association with the performance in the written calculation test. Specifically, both Dot matrix subtests, Listening recall, Spatial recall, and subtests that assess the level of processing, (Processing listening recall and Processing spatial recall), show a medium and positive correlation with the numerical Knowledge scale. Furthermore, the data show a small
Table 3. Correlation matrix between AWMA scores on the subscales and AC-MT 6-11-Skill Calculation Assessment Test $(\mathrm{N}=130)$

\begin{tabular}{|c|c|c|c|c|}
\hline \multirow[b]{2}{*}{$\begin{array}{l}\text { AWMA } \\
\text { subtests }\end{array}$} & \multicolumn{4}{|c|}{$\begin{array}{c}\text { AC-MT 6-11-Skill Calculation } \\
\text { Assessment Test }\end{array}$} \\
\hline & 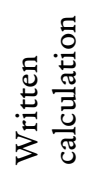 & 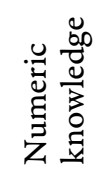 & 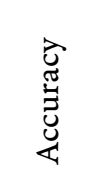 & 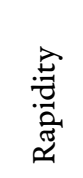 \\
\hline Digit recall & -.083 & .038 & .073 & .004 \\
\hline Dot matrix & -.050 & $.261^{* *}$ & $.187^{*}$ & .128 \\
\hline Listening recall & -.067 & $.246^{* *}$ & .111 & .038 \\
\hline Spatial recall & .142 & $.371^{* *}$ & .052 & $.149^{*}$ \\
\hline $\begin{array}{l}\text { Processing lis- } \\
\text { tening recall }\end{array}$ & -.052 & $.198^{*}$ & .079 & .031 \\
\hline $\begin{array}{l}\text { Processing spa- } \\
\text { tial recall }\end{array}$ & .091 & $.379^{* *}$ & .072 & .078 \\
\hline
\end{tabular}

relationship between the visual-spatial scales: Dot matrix and Spatial recall and respectively, the accuracy of measurement and the execution speed of the calculation test. The relationship between the Digit recall subtest and calculation ability doesn't seem significant.

\section{Analysis of the SAT family's moderation}

For the reading tests, the analysis showed that the attachment style with the parents moderates the relationship between verbal short-term memory and reading skills. Specifically, in the "Ambiguous/Disorganized" group, it is noticed that high scores in the Digit recall are associated with a reduction in errors, while higher achievement in the Listening recall subtest is associated with an increased execution time for the test (see Table 5). In the other two groups ("Secure" and "Insecure") the data follow the trend observed for all the selected participant.

With regard to the calculation tests, with reference to the main AWMA subtests, the data do not show moderation effects of the attachment style with parents and learning ability. The only significant effect was found for the Processing Spatial Recall subtest. In particular, the group with an "Ambiguous/Disorganized" attachment, shows a greater association between the this ability and the learning test with reference to the numerosity's assessment (one of the tests in AC-MT 6-11 - Skill Calculation Assessment Test), compared to groups with attachment "Secure" and "Insecure" (respectively: $r=.578, p<.01 ; \mathrm{r}=.367, p<.01$; 
$r=.273, p<.05)$. The Hommel correction analysis showed that all adjusted p-value were not significant.

Table 4. Correlation between AWMA subtests and reading performances Reading Test MT depending on the child's attachment style with his parents (SAT family)

\begin{tabular}{|c|c|c|c|}
\hline \multirow[b]{2}{*}{$\begin{array}{l}\text { AWMA } \\
\text { subtests }\end{array}$} & \multicolumn{3}{|c|}{ SAT Family - Parents attachmen } \\
\hline & 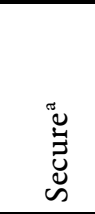 & 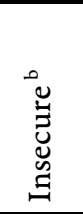 & 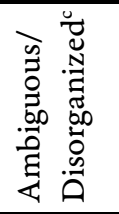 \\
\hline & \multicolumn{3}{|c|}{ Comprehension } \\
\hline Digit recall $^{\circ}$ & .055 & .054 & $.335^{*}$ \\
\hline Dot matrix & .035 & .191 & .189 \\
\hline Listening recall & .133 & .080 & .238 \\
\hline Spatial recall ${ }^{\circ}$ & .057 & .056 & $.326^{*}$ \\
\hline $\begin{array}{l}\text { Processing } \\
\text { listening recall }\end{array}$ & .064 & .129 & $.363^{*}$ \\
\hline \multirow[t]{2}{*}{$\begin{array}{l}\text { Processing } \\
\text { spatial recall }^{\dagger}\end{array}$} & -.003 & .052 & $.452^{* *}$ \\
\hline & \multicolumn{3}{|c|}{ Errors } \\
\hline Digit recall $^{\dagger}$ & .029 & $.239^{*}$ & -.294 \\
\hline Dot matrix ${ }^{\circ}$ & $.290^{*}$ & -.074 & $-.307^{*}$ \\
\hline Listening recall & -.029 & .036 & .124 \\
\hline Spatial recall & .038 & -.086 & -.118 \\
\hline $\begin{array}{l}\text { Processing } \\
\text { listening recall }\end{array}$ & -.095 & .127 & -.067 \\
\hline \multirow[t]{2}{*}{$\begin{array}{l}\text { Processing } \\
\text { spatial recall }\end{array}$} & .089 & .013 & -.059 \\
\hline & \multicolumn{3}{|c|}{ Time } \\
\hline Digit recall & -.061 & .202 & .018 \\
\hline Dot matrix & .137 & -.081 & -.034 \\
\hline Listening recall ${ }^{\dagger}$ & -.062 & .035 & $.422^{* *}$ \\
\hline Spatial recall & .169 & .070 & .135 \\
\hline $\begin{array}{l}\text { Processing } \\
\text { listening recall }\end{array}$ & .019 & .087 & .257 \\
\hline $\begin{array}{l}\text { Processing } \\
\text { spatial recall }\end{array}$ & .202 & .200 & .143 \\
\hline
\end{tabular}

\section{Analysis of the SAT school's moderation}

With regard to the reading tests, the analysis showed that attachment style with the teacher would moderate the relationship between short-term memory and reading skills. In particular, in the group showing an "Insecure" attachment, a greater ability in the Digit recall, Listening recall, Spatial recall and Processing spatial recall is associated with a greater text under-

Table 6. Correlations between AWMA subtests and Reading performance tests MT depending on the child's attachment style with his teacher (SAT school)

\begin{tabular}{|c|c|c|c|}
\hline \multirow[b]{2}{*}{ AWMA Subtests } & \multicolumn{3}{|c|}{$\begin{array}{c}\text { SAT school - Teacher } \\
\text { attachment }\end{array}$} \\
\hline & 䒕 & 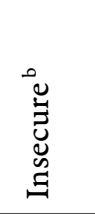 & 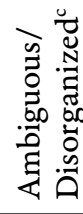 \\
\hline & \multicolumn{3}{|c|}{ Comprehension } \\
\hline Digit recall $\dagger$ & -.035 & .393 & .106 \\
\hline Dot matrix & .074 & $.352^{*}$ & .076 \\
\hline Listening recall $\dagger$ & .037 & $.449^{* *}$ & .228 \\
\hline Spatial recall $\dagger$ & -.008 & $.418^{* *}$ & .095 \\
\hline $\begin{array}{l}\text { Processing listening } \\
\text { recall }^{\circ}\end{array}$ & .081 & $.411^{* *}$ & .239 \\
\hline \multirow[t]{2}{*}{ Processing spatial recall $\dagger$} & -.068 & $.493^{* *}$ & .089 \\
\hline & \multicolumn{3}{|c|}{ Errors } \\
\hline Digit recall $\dagger$ & $.257^{*}$ & .037 & $-.293^{*}$ \\
\hline Dot matrix & -.050 & .035 & -.229 \\
\hline Listening recall & .030 & .068 & -.113 \\
\hline Spatial recall & .010 & -.090 & -.108 \\
\hline Processing listening recall & -.012 & .126 & -.131 \\
\hline \multirow[t]{2}{*}{ Processing spatial recall } & .106 & .057 & -.079 \\
\hline & \multicolumn{3}{|c|}{ Time } \\
\hline Digit recall & $.232^{*}$ & -.132 & -.126 \\
\hline Dot matrix & .064 & -.135 & -.059 \\
\hline Listening recall & .038 & .093 & .199 \\
\hline Spatial recall & $.314^{*}$ & -.045 & .000 \\
\hline Processing listen. recall & .049 & .109 & .145 \\
\hline Processing spatial recall & $.387^{* *}$ & .039 & .002 \\
\hline
\end{tabular}

standing (see Table 6). In addition, a similar trend was observed for the Processing listening recall test. In the group showing an "Ambiguous/Disorganized" attachment with the teacher, the ability in Digit recall was associated with fewer errors. No other significant 
effects were observed.

With regards to the calculation tests, the data show that the kind of attachment with the teacher influences the relationship between WM and learning in a marginal way (see Table 6-7). In particular, the group

Table 6. Correlation between AWMA subtests and ACMT 6-11 - Skill Calculation Assessment Test depending on the child's attachment style with his teacher (SAT school)

\begin{tabular}{|c|c|c|c|}
\hline \multirow[b]{2}{*}{ AWMA Subtests } & \multicolumn{3}{|c|}{$\begin{array}{c}\text { SAT school - Teacher } \\
\text { attachment }\end{array}$} \\
\hline & 节 & 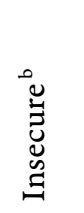 & 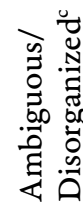 \\
\hline & \multicolumn{3}{|c|}{ Written calculation } \\
\hline Digit recall & -.102 & -.012 & -.110 \\
\hline Dot matrix & -.017 & -.143 & -.090 \\
\hline Listening recall & .041 & -.243 & -.161 \\
\hline Spatial recall & .005 & .042 & .264 \\
\hline Processing listening recall ${ }^{\circ}$ & .045 & $-.315^{*}$ & -.035 \\
\hline \multirow[t]{2}{*}{ Processing spatial recall } & -.011 & -.034 & .172 \\
\hline & \multicolumn{3}{|c|}{ Numerical knowledge } \\
\hline Digit recall & .063 & -.019 & .055 \\
\hline Dot matrix & .158 & .231 & $.404^{* *}$ \\
\hline Listening recall ${ }^{\circ}$ & $.370^{* *}$ & -.051 & $.308^{*}$ \\
\hline Spatial recall & $.260^{*}$ & $.312^{*}$ & $.411^{* *}$ \\
\hline Processing listening recall $\dagger$ & $.304^{*}$ & -.175 & $.373^{*}$ \\
\hline Processing spatial recall & $.292^{*}$ & $.295^{*}$ & $.475^{* *}$ \\
\hline
\end{tabular}

with an "Ambiguous/Disorganized" attachment shows a greater association between the ability in the Spatial Recall test and the Rapidity learning test (one of the learning tests in the AC- MT 6-11 - Skill Calculation Assessment Test), compared to groups with attachment "Secure" and "Insecure". A similar effect is observed between the Processing recall listening subtest and Numerical knowledge learning test (one of the tests in the AC-MT 6-11 - Skill Calculation Assessment Test) and between the Processing spatial recall subtest and the Rapidity learning test (one of the learning tests in the AC- MT 6-11 - Skill Calculation Assessment Test). Furthermore, we can observe two trends of moderation of the verbal short-term memory role, concerning the group with an "Insecure" attachment towards the teacher. In particular, this group shows no significant association between the Listening Recall subtests and Numerical knowledge

Table 7. Correlation between AWMA subtests and ACMT 6-11 - Skill Calculation Assessment Test depending on the child's attachment style with his teacher (SAT school)

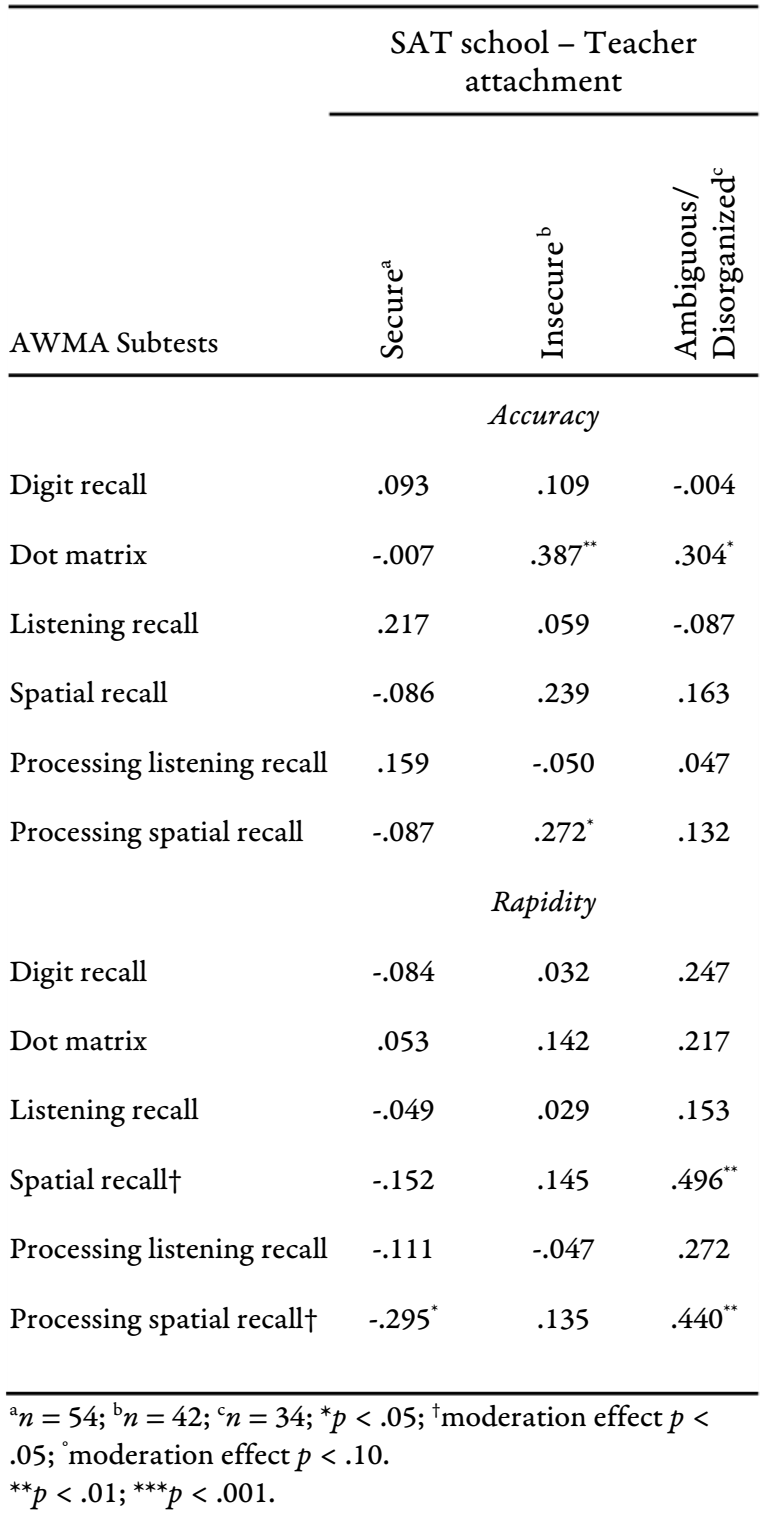

learning test (one of the learning tests in the AC- MT 6-11 - Skill Calculation Assessment Test) and shows a negative relationship between Processing listening recall and the Written calculation ability (one of the learning tests in the AC- MT 6-11 - Skill Calculation Assessment Test). The Hommel correction analysis showed that all adjusted p-value were not significant.

\section{Discussion}

A lot of studies highlight the possibility of considering the mother-child relationship as a structure within 
which is explained the teacher-child relationship, especially in the theoretical-operational interventions with risk children (Pianta, 1999). Moreover, both relationships (with the caregiver and with the teacher) are characterized by asymmetry in reference to responsibility, to power and skills; addiction protection and fulfill ment of teaching-learning needs of the child (Howes et al., 1998; Pianta, 1994).

This study shows that children with secure attachment with their caregivers tend, with more probability, to establish a secure attachment with their teacher (as previously discussed and shown in Table 1). Our results seem to be in line with other studies previously carried out (Begin, 2009; Howes, 1999; Pianta, 1997) and with the continuity and stability of the MOI highlighted by the Infant Psychopathology Research and development paradigm as well (Bretherton \& Munholland, 2008; Hope, 2010).

The results of this study confirm what is reported in the literature about the WM learning role. In fact, from the data analysis, a significant and positive association between WM skills and the performance achieved by the learning tests (both reading and calculation), was observed. The collected data suggest that the WM ability is associated with text understanding and numerical knowledge, and particularly with the children's ability to transform in digits and in the arrangement of digits in ascending and descending order, and in judging which of two numbers is the largest.

The main innovative aspect highlighted in this study, shows that the learning performance is not always related to the WM ability. The observed data show that this relationship is moderated by IWMs. This effect is even more remarkable when you consider that attachment style does not affect the WM operation, but it seems to have a relationship with the performance of the learning tests. More specifically, the analysis showed that attachment style with a child's own parents moderates the relationship between short-term verbal memory and the reading ability, however with respect to the calculation skill, the mo-deration effect is observed between the spatial processing component (Processing spatial recall) and the numerical knowledge (Numerosity assessment). Ultimately, in subjects with "Secure" and "Insecure" attachment the relationship between WM and performance is less strong, but in the group with an "Ambiguous/Disorganized" attachment style, the association between WM and performance becomes more important. Similarly, attachment style with the teacher moderates the relationship between the shortterm memory and reading skills, and it also moderate, in a marginal way, the relationship between WM and calculation ability. In particular, when the attachment style with the teacher is "insecure" there is a greater association between WM (in the Digit recall, Listening recall, Spatial recall and Processing spatial recall subtest) and the text understanding ability, while in the other two groups WM and performance seem com- pletely independent. With regard to the calculation tests, the data show that an "Ambiguous/Disorganized" attachment style, is characterized by a strong association between: the Spatial recall test ability and the Rapidity learning test, between: the Processing listening Recall subtests and Knowledge numerical learning test, and between: the Processing spatial recall subtest and the Rapidity learning test, however in the other two groups, WM and performance seem completely independent.

The parent-child and teacher-child relationship regulates the emotional skills and scholastic development of a child, having a significant influence on child's skills deficit or enhancement. The data reported in this study don't contradict the assumption that converging in a developmental conception in which the psychopathological, neuropsychological and cognitive disorders in an evolutionary age are interconnected (Levi, 2007).

This study provided theoretical and practical guidance to the teachers both for specific difficulties demonstrated by some children, and for the influence that their relationship with adults has on the mental and physical development of each child.

The authors of this study, members of the research group, proposed, as a future goal: to expand and enhance the research, and to widen the sample to validate and to allow the repeatability of the outcomes, because a part of our conclusion is only descriptive.

\section{References}

Ainsworth, M.D.S., \& Witting, B.A. (1969). Attachment and exploratory behaviour of one year-old child in a strange situation. In B.M. Foss (Ed.), Determinants of Infants Behaviour, (vol. IV). London: Methuen.

Alloway, T.P. (2007) Automated Working Memory Assessment Manual. Londra: Harcout Assessment.

Alloway, T.P. (2012). Can interactive working memory training improving learning? Journal of Interactive Learning Research, 23(3), 197-207.

Alloway, T.P., Gathercole, S.E., Willis, C., \& Adams, A.M. (2004). A structural analysis of working memory and related cognitive skills in early childhood. Journal of Experimental Child Psychology, 87, 85-106.

Alloway, T.P., \& Passolunghi, M.C. (2011). The relationship between working memory, IQ, and mathematical abilities in children. Learning and Individual Differences, 21(1), 133-137.

Alloway T.P. \& Temple K.J. (2007). A comparison of working memory skills and learning in children with developmental coordination disorder and moderate learning difficulties. Applied Cognitive Psychology, 21, 473-487.

Atkinson, R.C., \& Shiffrin, R.M. (1968). Human memory: a proposed system and its control processes. In K.W. Spence \& J.T. Spence(Eds.), The psychology of learning and motivation (vol. 2). New York: Academic Press.

Atkinson, R.C., \& Shiffrin, R.M. (1971). The control of shortterm memory. Scientific American, 225, 82-90.

Attili, G. (2001). Ansia da Separazione e misura dell'Attaccamento normale e patologico - Versione modificata e adattamento italiano del Separation Anxiety Test (SAT) di Klagsbrun e Bowlby [Separation Anxiety and assessment of normal and pathological attachment - Modified version and 
Italian adaptation of the Separation Anxiety Test (SAT) di Klagsbrun e Bowlby]. Milano: Edizioni Unicopli.

Baddeley, A.D. (2000). The episodic buffer: A new component of the working memory? Trends in Cognitive Sciences, 4, 417-422.

Baddeley, A.D., \& Hitch, G. (1974). Working memory. In G. Bower (Ed.), The psychology of learning and motivation. New York: Academic Press.

Baron, R.M., \& Kenny, D.A. (1986). The difference of the moderator-mediator variable in social psychological research: Conceptual, strategic and statistical considerations. Journal of Personality and Social Psychology, 51, 1173-1182.

Bergin, C., \& Bergin, D., (2009). Attachment in the Classrom. Education Psychology Review, 21,:141-170.

Bowlby, J. (1972). Attaccamento e Perdita, vol. 1: L'attaccamento alla madre [Attachment and Loss, vol. 1: The attachment to the mother]. Torino: Bollati Boringhieri.

Bowlby, J. (1975). Attaccamento e Perdita, vol. 2: La separazione dalla madre [Attachment and Loss, vol. 2: The separation from the mother]. Torino: Bollati Boringhieri.

Bowlby, J. (1983). Attaccamento e Perdita, vol. 3: La perdita della madre [Attachment and Loss, vol. 3: The loss of the mother]. Torino: Bollati Boringhieri.

Bretherton, I., \& Munholland, K.A. (2008). Internal Working Models in attachment relationships: Elaborating a central construct in attachment theory. In J. Cassidy \& P.R. Shaver (Eds.), Handhook of Attachment (2 ${ }^{\text {nd }}$; pp. 102-127). New York: Guilfrord Press..

Cassibba, R. (2005). L'intervento clinico basato sull'attaccamento [The clinical intervention based on the attachment]. Bologna: Mulino.

Cassibba, R., \& Caviglia, G. (2001). La relazione educatricebambino all'asilo nido: variabili rilevanti per il benessere del bambino [The teacher-child relationship in the daycare: relevant variables for the child's welfare]. Psichiatria dell'infanzia e dell'adolescenza, 67, 85-92.

Caviglia, G. (2003). Attaccamento e psicopatologia [Attachment and psychopathology]. Roma: Carocci.

Caviglia, G. (2005). Teoria della mente, attaccamento disorganizzato, psicopatologia [Theory of mind, disorganized attachment, psychopathology]. Roma: Carocci.

Caviglia G., \& De Coro, A. (2000). Ricerca empirica e cambiamento terapeutico: lo studio dell'attività referenziale fra psicoanalisi e psicologia cognitiva [Empirical research and therapeutic change: activity referential study between psychoanalysis and cognitive psychology]. In W. Bucci (2000), La valutazione dell'attività referenziale (De Coro, A., \& Caviglia, G. ) Roma: Edizioni Kappa.

Caviglia, G., Fiocco, B., \& Dazzi, N. (2004). La trasmissione intergenerazionale del trauma della Shoà: uno studio condotto con l'Adult Attachment Interview [The intergenerational transmission of trauma of the Shoà: a study performed through the Adult Attachment Interview]. Ricerca in Psicoterapia, 7(1), 67-83.

Caviglia, G., Iuliano, C., \& Perrella, R. (2005). Il disturbo borderline di personalità [The borderline personality disorder], Roma: Carocci.

Caviglia, G., La Marra, M., Sapuppo, W., \& Perrella, R. (2010). Automated working memory assessment e apprendimento nei bambini: una ricerca empirica [Automated working memory assessment and learning process in children: an empirical research]. Psichiatria dell'Infanzia $e$ dell'Adolescenza, 77(11), 38-47.

Caviglia, G., Perrella, R., Sapuppo, W., \& Del Villano, N. (2010). La ricerca in psicoterapia: il contributo del Gruppo di lavoro della Cattedra di Psicologia Dinamica della Seconda Università di Napoli [Research in psychotherapy: the contribution of the Working Group of the Chair of Dynamic Psychology of the Second University of Naples]. Re- search in Psychotherapy, 2(13), 32-52.

Cianchetti, C., \& Sannio Fancello, G. (2007). TVL - Test di Valutazione del Linguaggio [Language assessment test]. Trento: Erickson.

Cicogna, P.C. (1999). Psicologia generale [General Psychology]. Roma: Carocci.

Cohen, J., (1988). Statistical power analysis for the behavioral sciences. New Jersey: Lawrence Eribaum Associates.

Cornoldi, C., Lucangeli, D., \& Bellina, M. (2002). Test di valutazione delle abilità di calcolo [Arithmetic calculation abilities evaluation test]. Trento: Erickson.

Cornoldi, C., \& Colpo, G. (1998). Prove di lettura MT per la scuola elementare -2 [MT reading tests for primary school $-2]$. Firenze: O.S.

Curby, T.W., Rimm-Kaufman, S.E., \& Ponitz, C.C. (2009). Teacher-child interactions and children's achievement trajectories across kindergarten and first grade. Journal of Educational Psychology, 101(4), 912-925.

Dazzi, N., \& Vetrone, G. (2000). (Ed.). Psicologia. Introduzione per le scienze umane [Psychology. Introduction to the Humanities]. Roma: Carocci.

Del Villano, N., Cecere, C., Sapuppo, W., \& Caviglia, G. (2011). Una prova standardizzata di memoria di lavoro come previsione e miglioramento delle capacità di apprendimento nella pratica educativa [A standardized test of the working memory, as a prediction and improvement of the learning ability in educational practice]. Nuovi Orizzonti. Psicologia, Medicina, Pedagogia, III, 5-9.

Ebbinghaus, H. (1885). Memory. A contribution to experimental psychology. New York: Columbia Univerity Press.

Gray, P. (1994). Psychology (2 ${ }^{\text {nd }}$ ed.). New York: Worth Publishers Inc.

Hommel, G. (1988). A stagewise rejective multiple test procedure based on a modified Bonferroni test. Biometrika, 75, 383-386.

Howes, C. (1999). Attachment relationships in the context of multiple caregiver. In J. Cassidy \& P.R. Shaver (Eds.), Hanbook of attachment. Theory, research, and clinical application. New York: The Guiford Press.

Howes, C., Galinsky, E, \& Kontos, S. (1998). Child care caregiver sensitivity and attachment. Social Development, 7(1), 25-36.

Levi, G. (2007). I disturbi del bambino sono trasformabili? Moduli, connessioni, realtà rappresentazionale [Can child's disorders be changed? Modules, connections, representational reality]. Psichiatria dell'Infanzia e Dell'Adolescenza, 74, 451-458.

Liverta Sempio, O., Marchetti, A., \& Lecciso, F. (2001). Il SAT famiglia e il SAT scuola. Strumenti di misura dell'ansia da separazione da genitori ed insegnanti [The School SAT and the family SAT. Measuring tools for separation anxiety from parents and teachers]. Milano: I.S.U. Università Cattolica.

Main, M., \& Solomon, J. (1990). Procedures for identifying infants as disorganized/disoriented during the ainsworth strange situation. In M.T. Greenberg, D. Cicchetti \& E.M. Cummings (Eds), Attachment in the preschool years: Theory, research and intervention. Chicago: University of Chicago Press.

Meins, E. (1999). Sicurezza e sviluppo sociale della conoscenza nuove prospettive dell'attaccamento [Security and social development of the knowledge, new attachment perspectives]. Milano: Raffaello Cortina Editore.

Perrella, R. Semerari, A., \& Caviglia, G. (2013). Metacognition, borderline pathology and psychotherapeutic change: A single-case study. Research in Psychotherapy: Psychopathology, Process and Outcome, 16(2), 102-108.

Pianta, R., (1994). Patterns of relationships between children and kindergarten teachers. Journal of School Psychology, 32, $15-31$. 
Pianta, R.C. (1999). Enhancing relationships between children and teachers. Washington DC: American Psychological Association.

Pianta, R.C., Nimez, S., \& Bennet, E. (1997). Mother-child relationships, teacher-child relationships, and school outcomes in preschool and kindergarten. Early Childhood Research Quarterly, 12, 263-280.

Pianta, R.C., Belsky, J., Vandergrift, N., Houts, R.M., \& Morrison, F.J. (2008). Classroom effects on children's achievement trajectories in elementary school. American Educational Research Journal, 45(2), 365-397.

Sagi, A., Van IJzendoorn, M.H., Aviezer, O., Donnell, F., Koren-Karie, N., Joels, T., \& Harel, Y. (1995). Attachment in a multiple-caregiver and multiple-infant enviroments: the case of the Israeli kibbutzim. In E. Waters, B.E. Vaughn, G. Posada \& K. Kondo-Ikemura (Eds.), Caregiver, cultural, and cognitive perspectives on secure-base behavior and working models: New growing points of attachment theory and re search. Monographs of the Society for Research in Child Development, 244(60), 71-91.

Speranza, A.M, (2010). Disturbi della relazione e dell'attaccamento [Relationship and attachment disorders]. In M. Ammaniti (Ed.), Psicopatologia dello sviluppo.[Developmental psychopathology] (pp. 224-242), Milano: Raffaello Cortina Editore..

Tabachnick, B.G. \& Fidell, L.S., (1983). Using multivariate statistics. New York: Harper \& Row.

Tulving, E. (1985). How Many Memory System Are There?. American Psychologist, 40, 385-398.

van IJzendoorn, M.H., Dijkstra, J., \& Bus, A.G. (1995). Attachment, intelligence, and language: a meta-analysis. Social Development, 4(2), 115-128.

Submitted December 3, 2013

Revision received July 28, 2014 Accepted December 26, 2014 